\title{
Metal markets and recycling policies: impacts and challenges
}

\author{
Patrik Söderholm ${ }^{1}$ (D) Tomas Ekvall $^{2}$ \\ Received: 30 November 2018 / Accepted: 12 April 2019 / Published online: 8 May 2019 \\ (C) The Author(s) 2019
}

\begin{abstract}
An increased understanding of the existing markets for recycled (secondary) metals, including interactions with virgin material production, is essential for public decision-making processes concerning the implementation and evaluation of different categories of recycling policies. In this paper, we review the existing literature with the purpose of discussing (1) the impacts of various recycling policies on metal markets in which aggregate demand can be met by both primary and secondary production, and (2) a number of challenges that policy-makers need to confront in choosing between various types of recycling policies and policy designs. A simple partial equilibrium model is used as a pedagogical tool for shedding light on the impacts of tradable recycling credits, virgin material taxes, and recycling subsidies. In a second step, the paper identifies and discusses a few key challenges that policy-makers will need to address in recycling policy-making. These challenges include improving the functioning of secondary material markets by addressing various non-environmental market inefficiencies; identifying and designing (secondbest) policy mixes due to the presence of incomplete monitoring and enforcement of waste disposal behavior, and regulating environmental impacts through price- or quantity-based policies. Throughout the analysis, we consult the empirical literature on the functioning of scrap metal markets (e.g., steel, copper, and aluminum).
\end{abstract}

Keywords Metal supply and demand $\cdot$ Scrap metals $\cdot$ Market imperfections $\cdot$ Recycling policy

\section{Introduction}

During recent decades, an increasingly expanding global economy has led to concerns over the exploitation of the earth's natural resources, about the environmental impacts as well as about impending resource shortages (e.g., Hashimoto et al. 2012). The promotion of circular material use, including not least recycling and reuse, are deemed necessary in order to reduce the generation of waste and the economy's dependency on the extraction of primary (virgin) raw materials. Recycling of materials may save resources and energy, and delay the depletion of virgin natural resources.

In the metals industry, secondary (i.e., recycled) materials compete with primary materials, which depend on the extraction of non-renewable resources. Scrap materials, or

Patrik Söderholm

patrik.soderholm@1tu.se

$1 \quad$ Luleå University of Technology, Economics Unit, SE-971 81 Luleå, Sweden

2 IVL Swedish Environmental Research Institute, P.O. Box 5302, SE-400 14 Gothenburg, Sweden secondary metals in processed form, can sometimes be relatively cheap to produce compared to primary materials, at least in the cases where the scrap collection costs are not excessively high. Furthermore, the costs for exploration, mining, and primary refining have already been taken, and the energy requirements are lower. Moreover, as mining enterprises must resort to lower-grade, and more remote, mineral deposits, the costs of primary (virgin) material production may increase over time, ${ }^{1}$ therefore further improving the competitiveness of secondary metal production (Tilton 2000).

Due to the often high value of secondary metals, recycling of copper, aluminum, steel, etc. has been undertaken for almost as long as these metals have been used, and typically in the absence of any policy intervention. This has been the case for other secondary materials as well, including recycled newsprint and paperboard (e.g., Mansikkasalo et al. 2014). However, increased metal recycling may also face a number of barriers, such as failures to internalize the environmental external costs associated with primary metal production and use, and a lack of technological change facilitating the

\footnotetext{
${ }^{1}$ In the paper, the terms virgin materials and primary materials are used interchangeably.
} 
recyclability of various products (e.g., EEA 2017). The establishment of efficient secondary metal markets may also be hampered by incomplete information about the quality of various waste products (Nicolli et al. 2012; Milios 2018).

For this reason, in many countries, far-reaching policy instruments have been undertaken - and/or are plannedto promote further recycling of various secondary materials, and other efforts aiming at closing the material loops. For instance, in 2015, the European Commission adopted its Circular Economy Package, which includes legislative proposals on waste and a detailed action plan with measures covering the entire material cycle: from production and use to waste management and the market for secondary materials (European Commission 2015). Recycling policies often rely on price signals and economic incentives, e.g., surcharges on the disposal of recyclable products, tradable recycling credit schemes, subsidies to recycling programs, and virgin material taxes (e.g., Finnveden et al. 2012). Clearly, the assessment of the effectiveness and the efficiency of such policies must take into account the functioning of the already existing economic markets for the materials, and thus shed light on the relevant demand and supply responses. The respective policy impacts are complex also because while policies often are implemented at the national level, the affected economic markets, for instance, scrap metals, tend to be international in scope.

In this paper, we synthesize the existing literature with the purpose of discussing (1) the impacts of various recycling policies on metal markets in which aggregate demand can be met by both primary and secondary production, and (2) a number of challenges that policy-makers need to confront in choosing between various types of recycling policies and policy designs.

In achieving the first purpose, we use a (graphical) static partial equilibrium model describing the long-run interactions between primary and secondary production in satisfying a given (exogenous) material demand. This simple model is used as pedagogical tool for investigating the market impacts of three different types of recycling policies: tradable recycling credits, a virgin materials tax, and a recycling subsidy. We devote particular attention to the price responses and the resulting competition between secondary and primary production.

The second objective is achieved by drawing on the literature on addressing environmental externalities in waste management policy (Dinan 1993; Fullerton and Kinnaman 1995; Walls and Palmer 2001; Ino 2011). Efficient waste management policies, though, depend also on the presence of wellfunctioning economic markets for the recycled materials, i.e., markets characterized by low transaction costs, transparent information, etc. Still, a limited number of studies have analyzed various second-best cases, thus assuming that recycling markets are not operating due to the presence of high transaction costs, information failures, etc. (Calcott and Walls 2000, 2005; Fullerton and Wu 1998). ${ }^{2}$

Throughout the paper, we consult the empirical literature on supply and demand conditions in secondary material markets, and with strong emphasis on scrap metals. Specifically, quite a few econometric studies provide estimates of the ownprice elasticities of supply and demand. In the case of secondary metals, these have focused on copper, aluminum, steel, and typically on North American market conditions. The copper studies include, for instance, Bonzcar and Tilton (1975), Gómez et al. (2007), Slade (1980a, 1980b), and Stollery (1983), where the last two also investigate aluminum and steel recycling, respectively. Blomberg and Hellmer (2000) and Blomberg and Söderholm (2009) study the price responsiveness in the European secondary aluminum market, while the US steel scrap market has been analyzed by Barnett and Crandall (1986). ${ }^{3}$ Moreover, since recycled metal has represented a significant share of total metal consumed, econometric models of metal markets, aimed at studying primary metal supply and demand, often include descriptions of the associated secondary markets. Examples of such work are the copper studies of Fisher et al. (1972), Wagenhals (1984), Suan Tan (1987), and an early analysis of the aluminum industry by Charles River Associates (1971).

The analysis in the present paper draws on the results from these empirical studies of supply and demand behavior (e.g., own-price elasticities of supply and demand) in various metals markets. Still, it differs from the above studies - including previous literature reviews - in that it focuses in more detail on the impacts of three different types of policy instruments on the metal markets, explicitly taking into account the market interactions between virgin and secondary metal production (Sigman 1995; Palmer et al. 1997). ${ }^{4}$ In addition, we compare the possible market impacts of a global recycling policy versus the case of unilateral policies.

The paper proceeds as follows. In the next section, we outline the generic partial equilibrium model describing the interactions between primary and secondary production in

\footnotetext{
${ }^{2}$ See Nicolli et al. (2012) for ways to improve the functioning of (imperfect) secondary material markets, including the role of technological innovation.

${ }^{3}$ Econometric studies of supply and demand behavior in the wastepaper markets also exist (see Mansikkasalo et al. 2014 for a review). Some studies focus on the supply of wastepaper (e.g., Anderson and Spiegelman 1977; Edwards 1979; Kinkley and Lahiri 1984; Angus et al. 2012). Previous wastepaper demand studies include, for instance, Edgren and Moreland (1989), Nestor (1992), Samakovlis (2003), as well as Lundmark and Söderholm (2003, 2004).

${ }^{4}$ The analysis of secondary and primary material markets is also relevant in the context of an important methodological allocation problem in environmental life-cycle assessments (LCAs). Specifically, for a product life cycle that involves the inflow or outflow of recycled materials, the question arises to what extent the environmental burdens of primary material production and final waste disposal should be allocated to the product investigated (as opposed to other products where the material is used). These outcomes will in part be determined by supply and demand behavior in the material market (Ekvall 2000).
} 
satisfying a given overall material demand. This model is then used to investigate the various material market impacts of three recycling policies implemented at the global level in the international market: tradable recycling credits, virgin materials tax, and recycling subsidy. We also briefly comment on the case of a unilateral policy in only one country (or a subset of countries), not least discussing under what circumstances a national policy would affect the global material market as well as some important consequences if it does. In a final step, we identify a number of challenges that policy-makers will need to address in choosing between - as well as implementing various policy instruments and mixes. These challenges include improving the functioning of secondary material markets, designing efficient recycling policy instrument mixes, and regulating through price or quantity. Some concluding remarks and implications are provided in a final section.

\section{A simple model of primary and secondary material markets}

In this section, we outline a partial equilibrium model of the interaction between primary (virgin) and secondary material supplies to satisfy a given demand for material in the global market. As noted above, this model is primarily a workhorse and thus assists in illustrating some important long-run consequences of public policies introduced to promote an increased use of recycled materials. While the model is generic in the sense that it can be used in the context of various types of primary and second materials, we primarily draw on empirical experiences from the metals industries.

The model builds on (at least) four important assumptions. First, we assume that the primary and the secondary materials are perfect substitutes, i.e., there are no quality differences across these two materials. This implies that in the long run, the price of secondary material $\left(P_{S}\right)$ and the price of primary material $\left(P_{V}\right)$ will be equal. ${ }^{5}$ In principle, it would be straightforward to introduce a quality difference between secondary and primary materials, implying a long-run price premium for the high-quality - typically primary - materials. Such quality differences are important in choosing between, for instance, wastepaper and wood pulp. ${ }^{6}$ Nevertheless, modeling this explicitly would not alter the main results of our analysis in significant ways. In addition, recycled metal is often a near perfect substitute for primary metal in the sense that the properties of the materials, e.g., ductility and conductivity, are not lost when the metal is used and finally scrapped.

\footnotetext{
${ }_{5}^{5}$ Clearly, in the short-run, these prices could differ substantially due to, for instance, constraints on productive capacity as well as the management of inventories.

${ }^{6}$ There are differences in strength and purity, which restrict the use of wastepaper for many paper applications.
}

Second, the model assumes that the aggregate demand for material is perfectly own-price inelastic. While this is a relatively restrictive assumption, it can be noted that this elasticity is often low (albeit not zero). This is because the demand for materials is a derived demand, and normally the cost share of materials is low in many consumer products (Radetzki and Wårell 2017). Moreover, the processing of minerals and metals is typically very capital-intensive and substitution to other inputs is therefore costly, and takes a considerable amount of time (Tilton and Guzmán 2016). For instance, previous empirical estimates indicate that the own-price elasticities of steel and aluminum demand have been around -0.2 , while the corresponding elasticity for paper has been estimated at -0.4 (e.g., van den Bergh and Janssen 2005). This indicates, thus, that a $10 \%$ increase in the price of steel and aluminum may lead to a demand reduction by only about $2 \%$. Clearly, in the long run, the own-price elasticity could be considerably higher due to investments in (or lay down of) productive capital. Since our model makes the rather restrictive assumption of a price insensitive material demand, we also comment on some of the consequences of relaxing this assumption.

Third, we assume that the own-price elasticity of secondary material supplies is generally low. This is not a strong assumption; it has been confirmed in numerous empirical studies. For instance, in the case of secondary aluminum, previous estimates range from a low of about 0.20 (Blomberg and Hellmer 2000; Blomberg and Söderholm 2009) to a high of only 0.30 (Carlsen 1980). Fisher et al. (1972) and Slade (1980a, 1980b) assess the own-price elasticity of secondary copper produced from scrap in the $0.25-0.29$ range. Finally, Sigman's (1995) estimate of the own-price elasticity of recovered lead equals 0.25, while Barnett and Crandall (1986) report a corresponding estimate for steel scrap at 0.39 . Low own-price elasticities have been reported also for other types of materials. ${ }^{7}$ It should be noted, though, that overall these estimates are likely to primarily address short-run price responses. ${ }^{8}$ Nevertheless, as discussed in the next paragraph, for secondary materials, the long-run own-price elasticity of supply may not necessarily be higher than the corresponding short-run elasticity.

In general, low supply responses to price changes emerge because these supplies are heavily dependent on past consumption and construction patterns, and supply therefore

\footnotetext{
${ }_{7}^{7}$ For instance, own-price elasticity estimates for recovered paper supply have been found to range between 0.11 (Edgren and Moreland 1989) and only 0.30 (Edwards 1979). See also Mansikkasalo et al. (2014) for a synthesis of the empirical literature on wastepaper demand and supply elasticities.

${ }^{8}$ One reason for this interpretation is that most econometric studies of secondary material supply behavior rely on the use of time-series data (e.g., annual price observations). Time-series data are likely to mainly reflect short-run price responses (e.g., Baltagi 2005) and especially if there have been substantial price variations during the period under study (which typically is the case for secondary materials, such as metal scrap).
} 
constitutes an essentially fixed proportion of these economic activities. Furthermore, in the case of old metal scrap, i.e., scrap recovered from end-use products, it should be acknowledged that what is recycled from the stock of old scrap in one period is not available for recycling in the next period. This implies that the constraint imposed by the availability of old scrap could be more binding in the long run compared to the short run (e.g., Tilton 1992). Thus, even though in the long run, expansion of secondary processing capacity is possible (suggesting higher price responses in the long run), the longrun own-price elasticities of supply of, for instance, secondary aluminum or recovered lead may not necessarily be higher than the corresponding short-run elasticity. In addition, some generators of scrap materials, not least households, may face few incentives to increase their waste sorting activities even in the presence of significant price increases (e.g., Finnveden et al. 2013; Ekvall et al. 2014). In contrast, the own-price elasticities of primary material supplies are often low in the short run as existing productive capacity is fully utilized, but will be considerably higher in the long run when the level of capacity can be varied (e.g., new mines and processing plants can be developed) (e.g., Tilton and Guzmán 2016).

For the above reasons, it is fair to conclude that the slope of the secondary material supply curve is steeper than the corresponding supply curve for primary materials. In order to keep the model simple and easy to grasp, we introduce linear material supply curves. In practice, the supply curve for, for instance, old metal scrap is likely to be convex. Specifically, it will begin at a low price and can be relatively flat for the low production volumes, this since some scrap metal is of high quality and can be recycled at a low cost. Nevertheless, costs will rise notably as more of the old scrap is recycled, this since the additional supplies are scattered geographically, and some old scrap is a mixture of various kinds of scrap (in turn requiring costly identification and sorting techniques) (Tilton 1992). Nevertheless, our assumption of a linear and monotonically increasing supply curve does not alter the qualitative conclusions concerning recycling policy impacts.

Fourth, and finally, we assume the existence of an international (global) material market in which both secondary and virgin materials can be traded more or less freely across country borders. This is also a reasonable assumption for metal products such as copper, aluminum, and steel (Aylen and Albertson 2006; Ejdemo and Söderholm 2008). ${ }^{9}$ Given the competitive situation in most metals markets, it is therefore also fair to assume that material prices will be determined by the intersection of the demand and the (total) supply curves. Empirical work has provided support for the notion that most economic markets for primary and secondary metals are essentially global in scope. For instance, Aylen and Albertson

\footnotetext{
${ }^{9}$ There is also global trade in both wastepaper and plastic waste, in the latter case including substantial exports from the EU to China (e.g., Velis 2014).
}

(2006) showed that the US and European steel scrap prices have been cointegrated, i.e., they have followed the same long-term trend. In other words, although prices in the two regions may diverge because of different seasonal patterns, etc., the market forces will pull them back together in the long run (adjusting for the absolute level of the transport costs). ${ }^{10}$

Following the above, Fig. 1 displays a simple partial equilibrium model of the market for a given material, e.g., steel, copper, paperboard, etc. Here, $D$ represents the aggregate material demand curve, which indicates a fixed level of total quantity demanded at $Q . S_{S}$ and $S_{V}$ are the supply curves for the secondary and primary materials, respectively. The underlying total cost functions for these curves are assumed to be convex in quantity, thus resulting in upward-sloping marginal cost curves. The aggregate supply curve $S$ (in bold) has been obtained by the horizontal summation of the primary and secondary supply curves. The long-run market price for the material, $P$, will be set at the intersection of the demand curve and the aggregate supply curve.

At this market-clearing price, the quantity of secondary material supplied equals $Q_{S}$ while the corresponding quantity supplied from virgin sources is $Q-Q_{\mathrm{S}}=Q_{V}$ and where $Q$ represents total material demand. This shows, thus, that even in the absence of any policy intervention, the marginal cost of secondary material supply is low enough to, at least in part, crowd out some of the primary materials in meeting the exogenous aggregate demand. Indeed, this is a realistic description of most metals markets, where recycling efforts often are substantial. For instance, most of the available steel scrap is recycled and in 2017, the proportion of steel scrap used in crude steel production was $36 \%$ worldwide (e.g., Bureau of International Recycling 2018). Furthermore, for most recycled metals, a global industry has since long developed purely on the basis of profit incentives, and scrap prices are determined by demand and supply in these markets.

Still, since the early 1970s and onwards, far-reaching policy measures have been undertaken in many countries to promote additional recycling of different secondary materials. These include surcharges on the disposal of recyclable products, landfill regulations, $R \& D$ support, producer responsibility schemes, deposit-refund schemes, and subsidies to recycling programs (Palmer et al. 1997). For instance, already in 1979, the EU introduced the R\&D program RAWMAT, emphasizing the importance recycling urban and industrial waste, including non-ferrous metals (Gaballah and Kanari 2001).

\footnotetext{
${ }^{10}$ Aylen and Albertson (2006) also conclude that the US and European steel scrap prices have become more closely cointegrated over time, i.e., with presently fewer short-run departures from the long-run trend (see also Albertson and Aylen 1996).
} 
Fig. 1 Material market in the presence of primary and secondary material production



In the next section, we therefore employ the partial equilibrium model to provide a conceptual economic analysis of the potential impacts of various policies on the production of primary and secondary materials as well as on prices in the market.

\section{The market impacts of symmetric (global) recycling policies}

In this section, we analyze the impacts on the material market following the implementation of three different market-based recycling policies: (1) tradable recycling credits; (2) virgin materials tax; (3) recycling subsidy. As was noted above, we assume a symmetric (global) policy implementation, while the case of asymmetric (unilateral) policies is briefly discussed in the next main section. This is not meant to imply that we believe that it is likely that these policies will be implemented at a global level. Nevertheless, this approach is a necessary first step for grasping the market impacts of recycling policies regardless of whether these policies are implemented only in one country, in a selected number of countries (e.g., the EU Member States), or globally. In addition, for some materials (e.g., aggregates such as natural gravel, crushed rock, and sand), the geographical scope of the market is much more limited than in the case of metals (e.g., Söderholm 2011). For such cases, our model will also provide a relevant description of the functioning of such national (or regional) material markets (at least if these are reasonably competitive).

\section{Tradable recycling credit scheme}

We first investigate the market impacts of a so-called tradable recycling credit scheme. This type of policy imposes a minimum share (or level) of recycled content in a particular material and allows trading between the responsible firms to reduce (minimize) the cost of achieving this level. The specific design of this policy could vary, but we consider the case in which the credits are awarded to the companies that recover the recycled material, and then offer it to various product manufacturers. The manufacturers of the products containing the material would in this case be required to comply with a given recycled-content target. ${ }^{11}$ These could do the recycling themselves or they could purchase credits from others who have recycled more than their own obligation.

This type of policy has gained increased attention over the recent decades (Finnveden et al. 2012), and a prominent example is the scheme for tradable so-called Packaging Recovery Notes (PRNs) in the UK. This scheme was introduced in 1997 to implement the country's packaging regulation (O’Doherty et al. 2003). At the end of each regulatory period, each UK product manufacturer must hold enough PRNs for the regulated materials used for packaging to comply with the recycled content target. In the UK scheme, one unit of PRN has corresponded to 1 ton of a material recycled (e.g., Matsueda and Nagase 2012).

\footnotetext{
11 The company that pays for recovering the material may of course be the same as that which is required to use it in the production of new products. One example could be a newsprint mill, which both pays for the collection of old newsprint, and then complies with the recycled content target by employing this input to produce new newsprint.
} 
Fig. 2 The material market impacts of a tradable recycling credit scheme

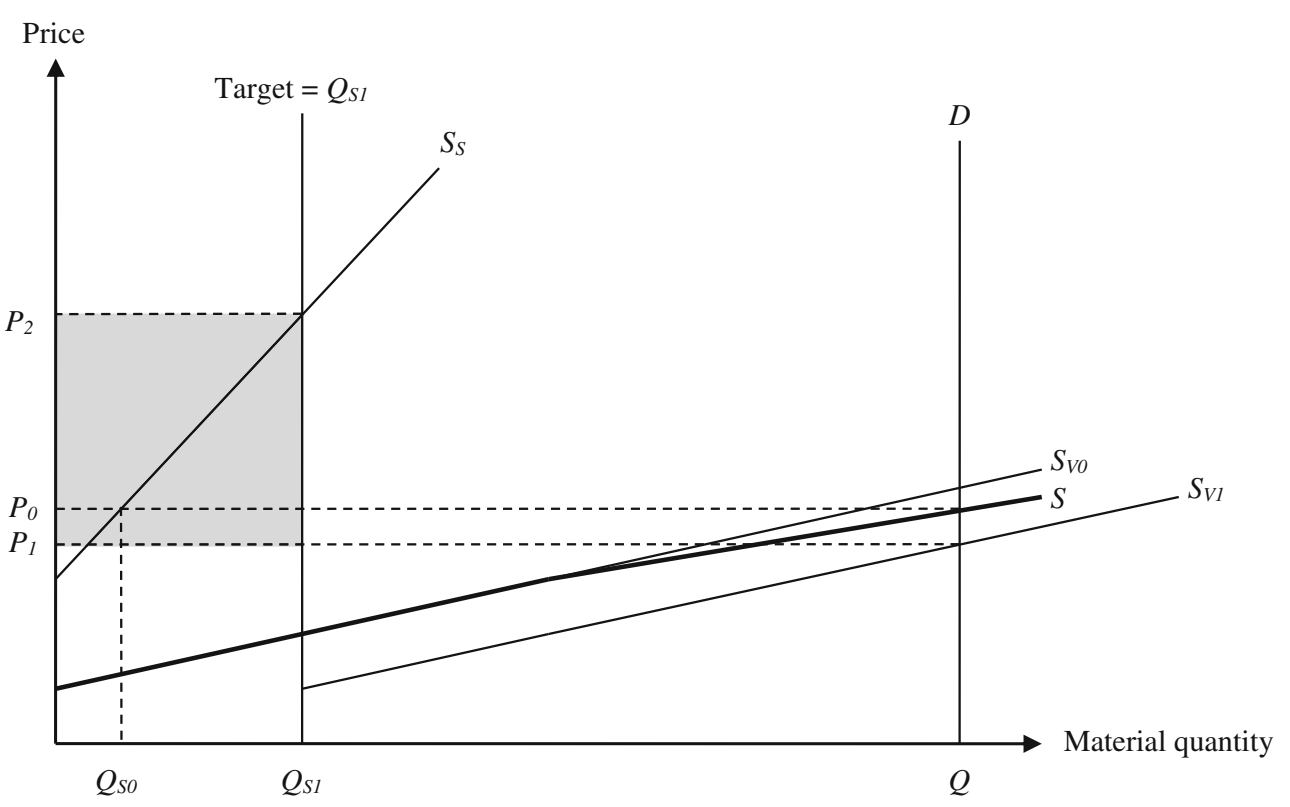

Figure 2 displays some relevant market impacts of this policy. ${ }^{12}$ The adoption of a minimum recycled-content target at $Q_{S 1}$ implies that the supply curve for primary materials must shift to the right by the same amount, i.e., from $S_{V 0}$ to $S_{V 1}$. The reason is that this target implies that a certain market share for recycled material is decided exogenously, and no virgin material can replace recycled material regardless of any changes in the market conditions. Moreover, the price faced by the producers of virgin materials will fall from $P_{0}$ to $P_{1}$, and at this new price, the generation of secondary materials increases from $Q_{S 0}$ to $Q_{S 1}$, while the corresponding generation of virgin materials decreases to $Q-Q_{S 1}$. When additional recycled materials are "forced" into the market, the marginal cost of ensuring that the remaining (residual) material demand is met will be lower than before.

In order to ensure that the target is met, and given the prevailing marginal cost of secondary material output, the generators of secondary materials must receive a total per unit revenue of $P_{2}$. Since they receive $P_{1}$ in the conventional material market, the unit price of the recycling credit will equal $P_{2}-P_{1}$. The shaded area in Fig. 2 corresponds to the total revenues from credit sales. The producers of the materialcontaining products can finance their purchases of recycling credits by levying an extra unit fee on final consumers, who are here assumed to be completely non-responsive to price changes. The material consumer price will then, in the absence of any transaction costs, equal $P_{1}+\left(P_{2}-P_{1}\right)\left(Q_{S 1} / Q\right)$, where

\footnotetext{
${ }^{12}$ For a more in-depth theoretical analysis of the UK tradable recycling credit scheme, see Matsueda and Nagase (2012). They also address this scheme's interaction with the UK landfill tax and conclude that these two policy instruments are not necessarily complementary in alleviating the country's landfill problem. Our representation of this policy is the one used by Carlén et al. (2005) and Söderholm (2008) in other empirical contexts (i.e., electricity).
}

the product consisting of the last two parentheses represents the fee that consumers will have to pay.

The above displays that the unit price of the recycling credit $\left(P_{2}-P_{1}\right)$ will be endogenously determined, and higher the steeper is the supply curve for secondary material. Indeed, as also noted above, in the presence of already high recycling rates, additional supplies of secondary materials can only be secured at a very high cost and thus high recycling credit price. The above also implies that any uncertainty about the position and the slope of the secondary material supply curve will translate into an uncertainty about the price of the recycling credits (this since the recycled-content target is fixed).

This result is important since the existing research shows that for most recycled materials, not least metals, the supply curve $S_{s}$ is relatively steep. Moreover, regulators typically have very limited information about the marginal cost of recycling. For this reason, if they set an ambitious policy target but underestimate the marginal cost of secondary material production, we could experience much higher recycling credit prices than was originally anticipated. Of course, recycling credit prices could also turn out to be considerably lower than expected. Indeed, if the recycled content target is low, and even turns out to be non-binding (i.e., set below $Q_{S 0}$ ), the long-run credit price would fall to zero (0).

Figure 2 illustrates how this specific policy intervention induces a material substitution effect in the sense that secondary materials substitute for the primary material. Still, even though the policy leads to a change in the consumer price, in our model there is no output effect due to the assumption of an exogenous material demand. Relaxing this assumption in the tradable recycling credit case will have a number of implications. Notably, the increase in consumer price for the material would be lower compared to the situation in Fig. 2 where the 
Fig. 3 The material market impacts of a virgin materials tax

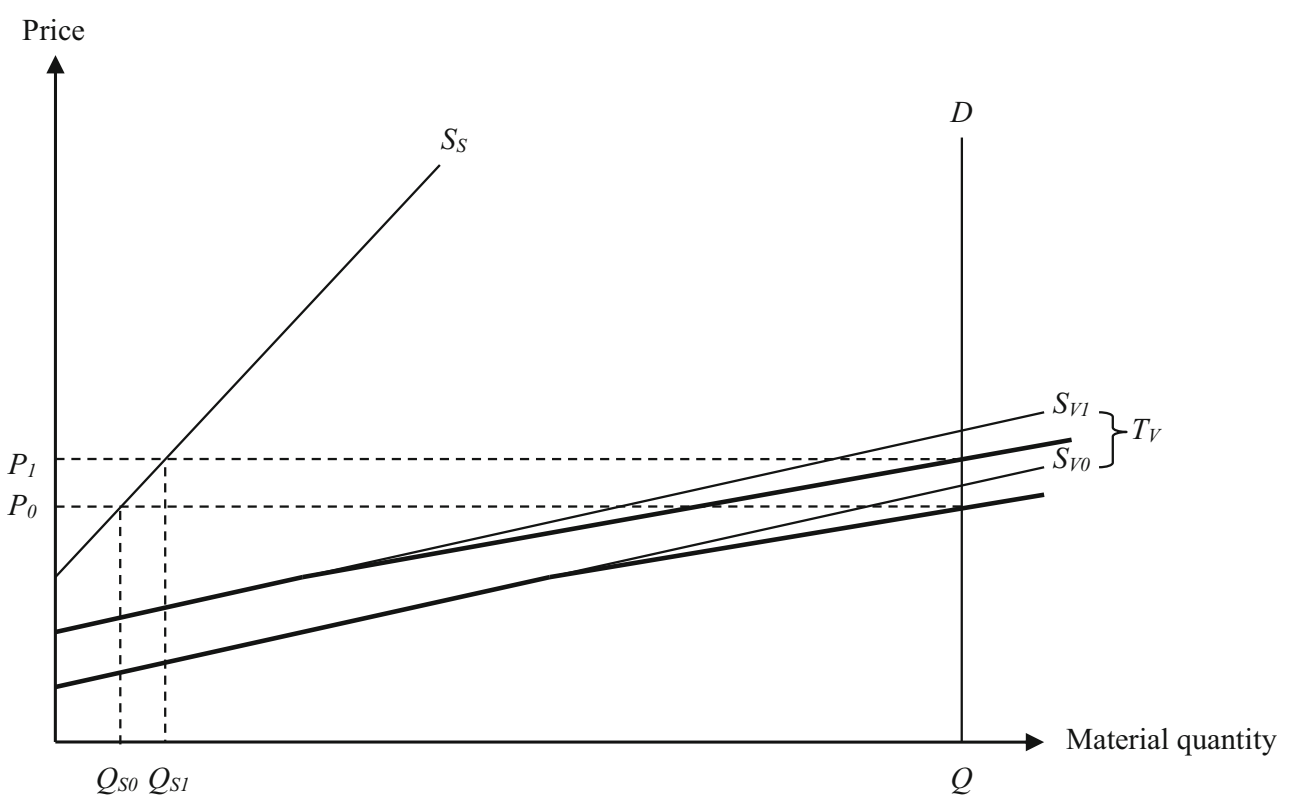

demand is completely own-price inelastic. Still, total material demand would fall, and this is likely to affect primary material production to a greater extent since this supply is more elastic than that for secondary material supply.

\section{Virgin materials tax}

A virgin materials tax is essentially a tax levied on each unit of the primary material supplied. Examples of such taxation approaches include the aggregates taxes in Denmark, Sweden, and the UK (Söderholm 2011). During the past decades, some policy-makers have argued that it would be desirable to extend the scope of the use of market-based instruments in environmental policy, not the least in the form of taxes on minerals, metals, and forest products. The European Commission has strongly advocated a broader scope for the use of market-based instruments among Member States. For instance, in the EU Thematic Strategy on the Sustainable Use of Natural Resources (European Commission 2005), the Commission called for greater decoupling of material use from economic growth and increased resource productivity. This could, it is argued, be achieved through taxes on various natural resources.

Figure 3 displays how a virgin material tax could affect the market for materials. We assume a tax $T_{V}$, which is imposed on the production (e.g., in tons) of the primary material. Such a tax implies an upward shift in the primary material supply curve, i.e., from $S_{V 0}$ to $S_{V 1}$, and in the aggregate (bold) supply curve. This leads to a higher long-run material consumer market price, $P_{1}$, and at this price, additional (non-taxed) secondary material production becomes profitable. Secondary material generation increases from $Q_{S 0}$ to $Q_{S 1}$. At the same time, the producers of primary materials will receive the market price exclusive of the tax, $P_{0}$, and primary material generation will therefore decrease from $Q-Q_{S 0}$ to $Q-Q_{S 1}$.

In contrast to the tradable recycling credit case, the impact on secondary material supplied in the market is here less direct. The tax on primary materials production induces a substitution of secondary materials for virgin materials. The virgin material tax represents a policy that increases the demand for secondary materials. However, due to the low own-price elasticity of secondary material supply, the impacts on actual use may be low unless the tax on primary materials is very high. ${ }^{13}$ Again, this could be the case for metal scrap in particular, where the market-driven recycling level $\left(Q_{S 0}\right)$ is high and additional supplies will be costly to bring to the market. ${ }^{14}$ The impact of a virgin materials tax on secondary material use will likely be even lower if we relax the assumption of a completely inelastic material demand. Similar to the case of tradable recycling credit case, taxing primary materials output would raise the overall long-run consumer price of the material and induce a reduction in aggregate material demand, something that in turn will dampen the price increase following the tax. For this reason, unless additional policies that increase the supply of recycled material, e.g., waste sorting requirements, are implemented, supply may not increase much even in the presence of a high demand.

\footnotetext{
${ }^{13}$ For instance, in Sweden, the tax on natural gravel has primarily led to a substitution of crushed rock for natural gravel, while the increase in the use of recycled material has been much more limited (e.g., Ministry of Finance 2003). Similar impacts have been reported in the UK and the country's aggregates tax (Legg 2007).

${ }^{14}$ Some old metal scrap may even be highly contaminated with other waste materials, and treatment costs are high as a result (Tilton and Guzmán 2016).
} 


\section{Recycling subsidy}

Recycling subsidies may come in many different forms, either as direct support to secondary material generation and/or as support to various types of infrastructures lowering the cost of collecting used products and materials. For instance, following the publication of the EU Directive on packaging and packaging waste (94/62/EC), the EU Member States have been undertaking major investments in their recycling systems, e.g., selective collection and sorting equipment and infrastructure. Still, while the Directive urges the industry to be responsible for their packaging end-of-life, incomes from local taxes have often been used to (at least in part) finance waste management (e.g., da Cruz et al. 2014).

Figure 4 illustrates the material market impacts of a specific type of recycling subsidy in the form of an extra per unit (e.g., ton) revenue, $R_{S}$, to secondary material generators. In our model, the implementation of such a recycling premium would shift the secondary material supply curve, $S_{S}$, downwards. This implies in turn that the aggregate material supply curve (in bold) will also partly shift downwards and to the right. The new equilibrium price becomes lower and equals $P_{1}$, and at this new price the secondary materials supplied increases to $Q_{S 1}$. The amount of virgin materials output decreases accordingly, i.e., from $Q-Q_{S 0}$ to $Q-Q_{S 1}$.

In contrast to the tradable recycling credit case, any uncertainty about the marginal costs of secondary material production will here translate into an uncertainty about the quantitative allocation between secondary and virgin material supplied in the market for the material. Clearly, any incomplete information about the marginal cost of primary material production will also add to this uncertainty about market outcomes. If the secondary material supply curve is very steep, a high subsidy will be needed to promote higher recycling levels. In the recycling subsidy case, the level of the subsidy, $R_{S}$, is exogenous while the quantity of the secondary material will be endogenously determined.

This last notion has key implications for the interaction between different types of recycling-promoting policies, such as between recycling subsidies on the one hand, and virgin material taxes and tradable recycling credit schemes on the other. The introduction of a global credit scheme would imply that other policies - either global or unilateral — would fail to affect the total use of secondary materials. For instance, if policy-makers implement a recycling subsidy as a complement to an existing tradable credit scheme, the additional cost of complying with the pre-determined recycled content target would decrease. However, the only impact on the market would be a fall in the price premium needed to secure enough of secondary material to meet the recycled content target, which remains fixed (unless this target is not binding and the scheme becomes entirely redundant). However, if instead a recycling subsidy is implemented in combination with a virgin materials tax, there would be no such complete crowding-out effect; both policies would help induce an increased demand for secondary materials.

Finally, the recycling subsidies differ from both tradable recycling credit schemes and virgin material taxes in the case where the assumption of a completely own-price inelastic material demand is relaxed. While the two latter policies lead to an increase in the consumer price for the material, the recycling subsidy instead implies a reduction in this price. Thus, with the introduction of a recycling subsidy, the aggregate material market will expand, thus implying a positive output effect and an overall higher level of material use. In other words, while all of the above studied policies encourage
Fig. 4 The material market impacts of a recycling material subsidy

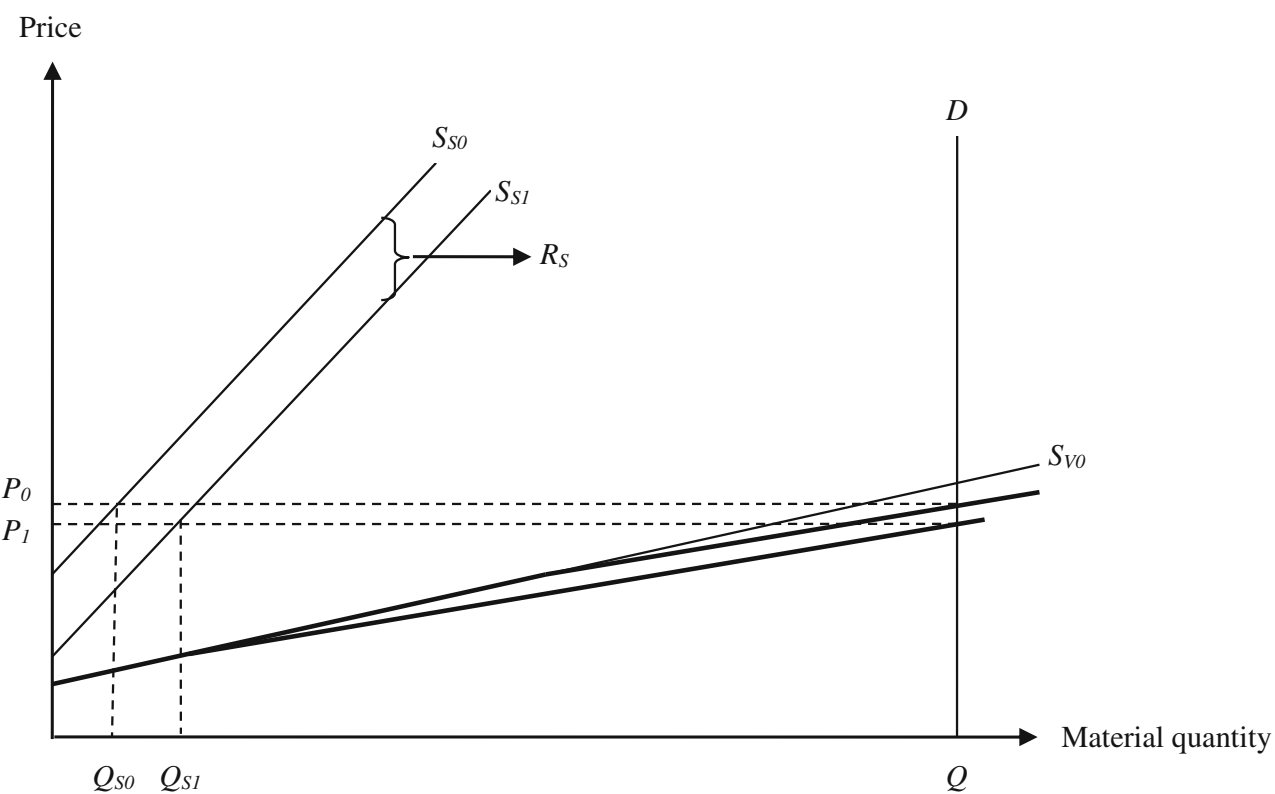


a material substitution effect in the presence of price-sensitive material demand, the three policies show some differences in terms of the direction of the output effect.

\section{The market impacts of asymmetric (unilateral) recycling policies}

In the previous section, we investigated the market impacts of global recycling policies, thus assuming that the policies are uniform across the countries that constitute the international material market. In this section, we relax also this assumption and briefly discuss the case of asymmetric - or unilateral-policies implemented in a materials market where there is no global recycling policy but where material prices are still assumed to be determined by global supply and demand patterns.

A unilateral recycling policy will lead to a compositional reorientation of the global supply and demand curves in the material market. Key questions are whether such a policy will affect the marginal conditions in the global market or not, and then how profound this effect will be. The answer to the first question is likely yes; one reason for this is that all countries are likely to confront price-inelastic secondary material supplies, in turn implying that unilateral policy efforts to increase the secondary material use are likely to lead to increased imports of such material from other countries. In a similar vein, if one country chooses to subsidize the supply of its secondary material supplies, other countries with more constrained supply situations are likely to be interested in importing this material. Still, the sizes of these market impacts will depend on the global market share of the country imposing the newand/or more stringent - policy. Of course, the implementation of unilateral policies in relatively small countries will only have very modest impacts on the market conditions in other countries. For many metals, e.g., steel, copper, and aluminum, a unilateral recycling policy could potentially influence the marginal conditions in the global material market, but the impacts on global price formation are likely to be modest at the most. Following these general remarks, it is useful to discuss how specific recycling policies that are implemented in one country (or a limited selection of countries) could qualitatively affect the market for primary and secondary materials.

In the case of a unilateral tradable recycling credit scheme, only the material consumers in the country implementing the policy will pay a premium fee on material purchases. An important question concerns whether only domestically collected material or all material supplied in the global market are eligible for complying with the country-specific recycled-content target. In the latter case, a unilateral policy may induce substantial imports of secondary materials from other countries, especially if the supply of these materials is constrained in the domestic market. Still, if the credit scheme is not combined with policies to increase the separation and collection of recyclable waste, the result would mainly be a geographical shift in the use of recycled and virgin materials (Oosterhuis et al. 2009).

In addition, the unilateral tradable recycling credit scheme will also cause the prices faced by both the secondary and virgin material generators in all other countries to decrease unless foreign secondary material production is eligible for recycling credits, thus implying that the supply of both materials will decline in the countries where no recycling policy is present. ${ }^{15}$ A corresponding effect will materialize in the presence of a unilateral recycling subsidy; this policy encourages increased use of secondary materials in the domestic market but also reduces the price of material, including that faced by all other countries. Since the supply of primary material production typically is more own-price sensitive than secondary material production, the former material is likely to be affected the most. Again then, in most cases, the magnitudes of such "crowding-out" effects are likely to be modest.

Finally, in the virgin materials tax case, a unilateral policy induces a substitution of secondary material for virgin material in the country that implements this tax. This could lead to imports of secondary material from countries in which there are no corresponding taxes in place. In contrast to the recycling credit case, though, a unilateral virgin materials tax would drive up the long-run material price in the global market, and in this way stimulate an expanded supply of both secondary and virgin materials in other countries. Still again, the positive effect on material recycling would be modest if the tax is not combined with supply-side policies.

\section{Policy challenges}

The previous sections have analyzed the market impacts of various recycling policies without, however, discussing the more normative question of what policies should be implemented in the first place. Clearly, this is a difficult policy choice, which needs to take into account the economic efficiency of various policies, the distributional effects, as well as various political and legal constraints. In the light of this, it is difficult to categorically endorse one recycling policy-or combination of policies - over another. In this section, we therefore refrain from outright policy recommendations. Instead, we discuss three challenges that policy-makers will need to confront in choosing between - and implementingvarious recycling policies, and point to important implications for the existing literature. These challenges are (1) improving

\footnotetext{
$\overline{15}$ Over time, though, strong recycling policies in significant regions of the world (e.g., the EU) could also lead to more fundamental structural shifts in the global material market. For instance, in the presence of a tradable recycling credit scheme in the EU, material consumers face a higher price. This could lead to a relocation of material-intensive industries to countries without such policies, in turn affecting supply and demand behavior at the global level.
} 
the functioning of secondary material markets by addressing various market inefficiencies, (2) designing (second-best) policy instrument mixes in the presence of incomplete monitoring and enforcement of waste disposal behavior, and (3) regulating through price or quantity. It should be noted that our discussion is general in scope with some empirical examples from the metals markets. Of course, though, certain market failures may be more relevant in one metal or material market compared to another. Empirical studies of the significance of market failures in various secondary metal markets represent an important avenue for future research.

\section{Improving the functioning of secondary material markets}

Policies to promote an increased use of recycled materials can take many different forms. In this paper, we have so far focused on investigating explicit recycling policies and their impact on the market. Still, our analysis assumed that the respective markets are perfectly efficient, and thus operate very well in the sense that all gains from trade within or between countries would be fully exploited. For some materials, e.g., steel scrap and secondary aluminum, this is - at least in part-a reasonable assumption. Still, for many other recycled materials (e.g., plastics, rubber, and specialty metals), the economic markets may be underdeveloped and/or inefficient (see also Milios 2018). Below, we briefly discuss four different types of sources of market inefficiencies that may impede the use of secondary material use. We also briefly comment on how these inefficiencies can be remedied through policy action.

First, all of the negative environmental externalities arising from primary material extraction (e.g., air and water pollution, climate change), and/or waste management (e.g., leaching into the groundwater) may not be internalized adequately, e.g., through standards and/or taxes. One reason for this could be a reluctance among policy-makers to impose stringent regulation on industries that face intense competition in global markets. In addition, many regulations of downstream waste, such as taxes on waste disposal, are simply difficult to implement due to the regulators' inability to observe, measure, or monitor improper waste disposal behavior.

For this reason, rather than regulating emissions and waste generation and disposal as close to damage done as possible, the environmental authorities may support specific activities-i.e., material recycling - that can be assumed to correlate with reduced environmental load. This could involve various policy efforts that more directly aim at closing the material cycles and promote a circular economy in which the value of products, materials, and resources are maintained, not least through the recycling and re-use of primary materials (Heshmati 2017). As noted below, this approach may require a mix of policy instruments that affect both the supply and the demand side of the materials market.
It is important to emphasize that from an economic efficiency perspective, circularity, metal recycling, and/or higher material efficiency are not necessarily important policy objectives in themselves; policies that support these are, as noted above, typically "second-best" remedies to the underlying market imperfections. For instance, promoting material efficiency through a policy that extends the lifetimes of products could have impacts on the economy that are very difficult to anticipate. Longer lifetimes imply a slower rate of capital turnover, but also then a lost opportunity to produce more energy- and material-efficient products. Such a policy could then also reduce the incentives for the producers to engage in $\mathrm{R} \& \mathrm{D}$ that makes their products more energy and material efficient. As a result, the net environmental impacts of the product-life-extension policy can well be ambiguous. Another example concerns the role of policy in saving virgin natural resources; such policies may not necessarily achieve this goal since they decrease the economic availability of such resources. For instance, a tax on metals extraction would make exploration activities less favorable, and a tax on virgin forest materials would reduce the incentive to plant new forests.

This illustrates the importance of targeting existing environmental externalities as closely as possible. Indeed, a particularly important consideration for policy is to stimulate technological development that can facilitate cheap monitoring of diffuse emissions (e.g., Söderholm and Christiernsson 2008). Such development would permit the implementation of policies that can directly target the relevant environmental externalities. Moreover, institutional reforms that reduce the transaction costs involved in implementing such policies are also important.

Second, efficient markets build on the presence of wellinformed producers and consumers. In practice, however, there may be profound information inefficiencies in secondary material markets, not least about the quality of waste such as the structural strength of old metal scrap. One source of inefficiency is the presence of so-called asymmetric information, i.e., where one party involved in a transaction (typically the seller) has more information than others (i.e., consumers), but are unable to perfectly transfer this knowledge (Akerlof 1970). In the context of recycled materials markets, buyers often face uncertainty about the quality of the material, which is (at least partly) unobserved. This risks leading to a situation where primarily low-quality materials are supplied in the market place (so-called adverse selection).

The use of long-term supply contracts can be one way of dealing with this problem; it reduces the sellers' incentives to misrepresent the materials being sold. For instance, the steel scrap market has historically been segmented between occasional sellers (i.e., that would experience fewer potential adverse reputation effects from selling low quality waste) and more regular and frequent sellers (for whom such effects are likely to be significant and negative) (Nicolli et al. 2012). There could also be a 
case for the government to introduce ex post liability rules, which penalize the misrepresentation by sellers in secondary material markets, and/or support various dispute settlement mechanisms.

Third, while the above information inefficiency relates to sources of recycled materials at the input stage, material buyers could also have incomplete information about the suitability of a given waste fraction for a particular application. This can be a challenge, particularly in the use of recycled plastics, construction and demolition waste, and occasionally also for paper and glass (Reid 2003; Symonds et al. 1999; Ecotec 2000). In addition, even metal scrap can be contaminated with rubber, glass, wood, and other metals (e.g., Tilton and Guzmán 2016).

Inaccurate perceptions of the nature of material quality arise in large part from the imperfect internalization of so-called adoption externalities in the relevant markets. For instance, the early adopters of recycled materials in new application generate information that is of value to others, and that information is a public good that can be appropriated by these at a low (or no) cost. Still, since this economic value is not rewarded in the market, early adoption may be lower than the level that will be economically efficient (e.g., Jaffe et al. 2003). One potential regulatory response is the use of performance standards that are generic across products, whether manufactured from primary or secondary materials (Nicolli et al. 2012). In addition, public procurement of products based on recycled materials as well as public support to pilot and demonstration projects can also play an important role in overcoming the problem of adoption externalities in secondary material markets.

Fourth, and finally, one important non-environmental market failure, which can impede the use of recycled materials is where one company manufactures a product in a manner that does increase the cost of recycling for downstream processors (or inhibits recycling in some other way) (Calcott and Walls 2000). For instance, metal applications, such as pigments in paints and as minor constituents in alloys, have occasionally made some materials uneconomical to recycle (e.g., ICME 1996). There may exist no means through which the recovery facility can provide the manufacturer with any incentives to alter the design of the product. In practice, it is difficult for policy-makers to attain a first-best outcome in addressing this market failure, e.g., since product-specific taxes that vary with the degree of recyclability are difficult (and costly) to implement. Producer responsibility schemes could address product design issues, e.g., removing - or reducing the weight of packaging materials. Still, strong incentives for more efficient design of products for recycling could require that owners of recycling facilities keep track of exactly which firms' products they are recycling (Walls 2003). ${ }^{16}$

\footnotetext{
${ }^{16}$ Existing producer responsibility schemes typically involve only a collective responsibility to address product recyclability issues (e.g., O'Doherty et al. 2003; Hage 2007).
}

\section{Designing policy instrument mixes}

The discussion in the previous sub-section displayed how the establishment of efficient recycled material markets could be hampered by a combination of various environmental as well as non-environmental market failures, i.e., the latter related to information asymmetries, incentives for product design, etc. A multitude of market failures may require the adoption of policy instrument mixes, e.g., environmental taxes and regulations combined with product standards and support to various $\mathrm{R} \& \mathrm{D}$ efforts, at least in those cases where the private actors fail to introduce suitable remedies on a voluntary basis. In this sub-section, we provide yet another rationale for the use of policy instrument mixes in material markets. Specifically, many of the environmental impacts arising from material production and use are diffuse and difficult to monitor and therefore also to regulate. Society therefore has to find alternative - yet more indirect - ways of regulating them, in turn often requiring a mix of various policies.

Environmental authorities need to regulate improper disposal of various types of waste since this would assist in addressing a number of important environmental externalities, such as chemical risks, air and water pollution, etc. The environmental economics literature concludes that charges or taxes that can target these externalities as closely as possible, e.g., a weight-based tax on waste disposal, would represent the most efficient policy response (Walls and Palmer 2001). ${ }^{17}$ Such a policy would - in principle - provide incentives not only for proper waste disposal but also for reduced production of waste-generating products. Still, as noted above, waste disposal behavior is typically clandestine and difficult to detect. ${ }^{18}$ Regulators are simply often unable to observe, measure, or monitor such behavior.

Eichner (2005), Fullerton and Wu (1998), Walls and Palmer (2001) as well as Palmer and Walls (1999) conclude that no single policy instrument can alone generate the economically efficient level of both the downstream and upstream waste disposals. For instance, a tax on virgin material will primarily address the external cost resulting from extracting or harvesting virgin materials, but generally not for the corresponding costs resulting from waste disposal. Such a tax would reduce the production of waste-generating material, but it would not provide the consumers of products containing these materials with any incentives to dispose of used products in an environmentally friendly way. However, under these

\footnotetext{
${ }^{17}$ However, in real-life settings, other policy instruments could be preferred. Andersson and Stage (2018) report using Swedish data that a system of collecting food waste separately can be more effective than imposing weight-based waste tariffs in respect not only of reducing the amounts of waste destined for incineration but also of increasing materials recycling and biological recovery.

${ }^{18}$ Upstream external environmental costs are instead often easier to control and regulate, including, for instance, emissions into air and water from stationary industrial plants.
} 
circumstances, a policy mix can be (roughly) equivalent to an environmental damage tax on the unobservable activity (e.g., Bennear and Stavins 2007).

Previous research has suggested that a tax on virgin resources in combination with a recycling subsidy ought to be a relatively efficient second-best policy (Fullerton and Kinnaman 1995; Dinan 1993; Walls and Palmer 2001; Ino 2011). The virgin materials tax discourages the production of waste-generating products. Furthermore, if the tax is assessed per pound of intermediate material produced, it will also provide producers of these materials with the incentives to produce lighter-weight products. This would reduce the amount of materials entering the solid waste stream, while the recycling subsidy encourages the substitution of secondary materials for virgin materials (e.g., Palmer and Walls 1999). Such a policy mix resembles a deposit-refund system in which the deposit acts like a tax on the virgin material, while consumers who choose to recycle get the refund back. ${ }^{19}$ In this way, a virgin materials tax and a recycling subsidy would be policy complements rather than substitutes. ${ }^{20}$

Söderholm (2011) provides a relevant empirical illustration from the taxation of aggregates in three European countries: Denmark, Sweden, and the UK. While these taxes have reduced the use of nature gravel, sand, etc., they often only induce a limited use of recycled materials since the own-price elasticity of supply for these materials is low. Moreover, generators of recycled materials may have few incentives to increase their material sorting activities in the presence of a tax on virgin materials. In other words, unless additional policies to increase the supplies of recycled material are implemented, i.e., that can alter the position as well as the slope of the secondary material supply curve, supply cannot increase much even in the presence of a high demand.

In Denmark, the aggregates policy has addressed this policy challenge. Here, an aggregates tax is (since 1990) levied on raw materials that are commercially extracted and consumed in the country or commercially imported (Nordic Council of Ministers 2002). These include, among others, sand, gravel, stones, peat, clay, and limestone. The tax has induced a marked increase in recycling, in particular of construction and demolition waste. In $1985,82 \%$ of the construction and demolition waste was landfilled and only $12 \%$ recycled, but in 2004, the recycling rate had increased to around $94 \%$ (EEA 2008). An important precondition for this

\footnotetext{
${ }^{19}$ Palmer et al. (1997) show empirically, and in the context of recycling of aluminum, steel, and other materials, that a deposit-refund scheme would be more cost-effective than both a virgin material tax and a recycling subsidy used in isolation. See also Sigman (1995) for a similar application to the case of lead recycling.

${ }^{20}$ In promoting a circular economy that aims at closing material loops and increasing resource efficiency, other components of the policy mix may also be necessary, such as policies for repair and increased durability (Milios 2018). See, however, above and in Söderholm and Tilton (2012) for critical remarks on policy instruments that directly aim at prolonging product lifetimes.
}

was the introduction of a supply-oriented policy instrument that complemented the virgin material tax. In 1997, a regulation on the separation of construction and demolition waste was enacted stipulating that waste from demolition works involving more than 1 ton of such waste should be separated at source into pure fractions. This has increased the ease with which secondary material supplies can be utilized in construction works, etc. The resulting policy instrument mix is therefore consistent with the objective of targeting both upstream and downstream impacts.

In contrast, the adoption of recycled materials in the aggregates sector has been more modest following the implementation of the Swedish and the UK aggregates taxes (e.g., Söderholm 2011). This has in part been a result of limited requirements for waste source separation at building and demolition sites, etc. In addition, in the 1980s, Sweden experienced an expansion in house and road building. For this reason, the prevailing stock of infrastructure has had a low replacement rate, and policies forcing recycling rates for, for instance, construction and demolition waste to increase will be ineffective (Legg 2007).

\section{Regulating through price or quantity}

While the above discussion has emphasized that various types of policy instruments are likely to complement each other in promoting efficient materials markets, it is also useful to discuss the choice of policy responses in cases where various instruments are substitutes. In this final sub-section, we address the choice between instruments that regulate the quantity of recycled materials versus those that instead affect the relative price of secondary versus virgin material. Specifically, the virgin material tax and the tradable recycling credit scheme are essentially policy substitutes in that they both induce an increased demand for secondary materials. As noted above, a key difference lies in the fact that in the latter case, the quantity of secondary material use is fixed and the price of the recycling credit is endogenously determined and uncertain. In the virgin material tax case, though, the tax level is fixed while the outcome in terms of secondary material use is uncertain.

In a situation where the regulator possesses complete information about the marginal costs of secondary and virgin material production $\left(S_{S}\right.$ and $\left.S_{V}\right)$, both policies could easily be designed to generate the same market outcome in terms of secondary material use. For instance, for a given recycledcontent target, it would be easy to implement a tax at a level just high enough to comply with this target. However, the environmental economics literature recognizes that regulators' knowledge about marginal costs is often far from complete, and such uncertainty is critical for the choice between these types of policies (e.g., Goulder and Parry 2008).

As noted above, emphasis may be put on either regulating quantities or prices. Previous work shows that if the marginal 
costs of secondary material production are uncertain but can be expected to rise steeply with increased recycling levels compared to the marginal benefits of recycling (i.e., the avoided environmental damages), economic efficiency speaks in favor of a price-based over a quantity-based policy. ${ }^{21}$ The economic case for a quantity-based policy, e.g., tradeable recycling credit schemes, would however be stronger if the marginal cost curve for recycled materials is relatively flat and the marginal benefits of increased recycling involve critical thresholds and thus increase significantly with more intense recycling levels. In this latter case, it would be important to fix the quantities in order to avoid the risk of significant environmental damages (of not recycling enough).

Overall, it is easier to argue that the former situation applies to material recycling, thus calling for, for instance, the adoption of virgin materials taxes rather than tradable credit recycling schemes. We have already noted that the ownprice elasticity of secondary material supply tends to be low, thus suggesting a relatively steep marginal cost curve. Furthermore, although an increased use of recycling may avoid the spread of hazardous substances in specific cases, the environmental benefits of material recycling are overall not likely to exhibit significant threshold effects. On occasion, material recycling may even cause increased discharges of hazardous substances, not the least when involving the processing of materials of mixed and uncertain qualities (e.g., Nicolli et al. 2012).

In sum, the above suggests that price-based material recycling policies may in general be more economically efficient that quantity-based ones. Nevertheless, the choice between priceand quantity-based policy approaches is likely to depend on the specific context (e.g., material, geographical location).

\section{Concluding remarks and avenues for future research}

During the last decades, recycling of a wide array of materials, ranging from food product waste to advanced products such as cars and computers, has become part of everyday life, and a wide array of policies have been implemented to increase material recycling rates. Due to the often high value of some recycled materials, not least scrap metals, recycling has been undertaken for virtually as long as these materials/metals have been used, and typically in the absence of any policy intervention. Indeed, for many secondary materials, a global industry has developed on the basis of profit motives, and prices have been determined by demand and supply in the markets. In the light of this, this paper takes stock in the notion that an increased understanding of

\footnotetext{
${ }^{21}$ The seminal study on this issue is Weitzman (1974). See also Adar and Griffin (1976) and Stavins (1995) for more recent applications in the context of environmental policy.
}

scrap market behavior, including any interactions with the market for virgin materials, is essential for the involved producers and users of scrap as well as for the public decision-making processes concerning the design, implementation, and evaluation of different policy instruments.

In the paper, we synthesized the existing academic literature to discuss the functioning of economic markets in which material demand can be satisfied by both primary and secondary production, as well as the market impacts of three different recycling policies. We adopted a simple partial equilibrium model and showed that all of these policy instruments induce a substitution of secondary materials for virgin materials, if globally implemented. However, previous empirical studies display generally low own-price elasticities of secondary material supplies, not least for scrap metal, implying that this substitution effect may be modest in the case of a virgin materials tax. Alternatively, the premium price needed to fulfill a given quota for secondary material use could be high in the case of a tradable recycling credit scheme.

The paper also discussed the possible impacts of a unilateral (country-specific) recycling policy in the presence of a global material market. Such a policy will only significantly affect the global market if the domestic market is large enough to influence prices in the global market. For several recycled materials, such as steel scrap, secondary copper, etc., this is often not the case. The analysis displayed some market consequences in the situation where the unilateral policy can be assumed to have notable impacts on the global market. We show in particular how a tax on virgin raw materials or the implementation of a tradable recycling credit scheme in one country may induce higher imports of recycled materials from other countries where such a policy is absent. Still, if policy instruments to increase the separation recyclable wastes (and hence increase the own-price elasticity of secondary material supply) are lacking in the exporting and the importing country, a domestic virgin materials tax or tradable recycling credit scheme would potentially in large part only lead to a geographical shift in the use of recycled and virgin materials.

Finally, while the paper has emphasized - and illustrated - that the implementation of various recycling policies must take into account the functioning of secondary and primary material markets, it also identifies a number of additional challenges in choosing efficient policies and policy mixes. These challenges include the presence of different types of non-environmental externalities, e.g., information failures related to waste quality, and technological externalities related to the products from which secondary materials are derived, each of which may require specific policy attention. Moreover, addressing the various environmental externalities directly is often difficult due to the cost of monitoring and regulating waste 
disposal behavior. Instead, policy may have to build on a combination of policy instruments that addresses both the upstream and the downstream constraints. Specifically, demand-side instruments such as virgin material taxes will generally not be able to simulate secondary material demand cost-effectively unless additional policies to increase the supply of recycled material, and its own-price elasticity, are implemented.

Clearly, additional research on the functioning of recycled material markets, and the inter-action between the different public policies influencing these markets, is motivated. There is a need for research investigating the significance of various types of market failures in different markets. For instance, and as indicated above, informational market failures may be prevalent in some material markets (e.g., building and demolition waste), but less so in other markets (e.g., scrap metals). Moreover, given the difficulties in closely targeting some of the nonenvironmental and environmental market failures, the issue of technological innovation in the material recycling sector as well as the role of public policy in inducing innovation efforts should be a particularly important research endeavor. Technological innovation that permits better tracing and tracking of materials, waste, and pollution is needed, e.g., implementing environmental regulations that are close to damages demand specific monitoring technologies that can measure and monitor waste and pollution levels along the life cycle of products. Still, it is quite unclear who has the incentive to promote and undertake such R\&D activities. Private firms cannot be expected to pursue these types of green innovations intensively, unless the government promotes such activity. Still, governments may often spend substantial amounts on funding R\&D on pollution mitigation technology, but public programs that fund research on technologies that can facilitate policy enforcement and environmental monitoring are typically less common.

Furthermore, the analysis has been static in the sense that it does not explicitly address the dynamics of primary material development (i.e., exploration incentives, resource depletion), and the links between secondary material supplies on the one hand and historical consumption patterns on the other. Addressing these issues, and how they could affect the longrun impacts of various recycling policies, also represents an important avenue for future research.

Acknowledgements The research undertaken in preparation of this paper has formed part of the multi-disciplinary research program "Towards Sustainable Waste Management," hosted by IVL Swedish Environmental Research Institute and funded by the Swedish Environmental Protection Agency, as well as of the EU ERA-Net Sumforest project BenchValue (Formas Grant Number 2016-02113). Constructive comments from one anonymous reviewer are gratefully acknowledged. Any remaining errors, however, reside solely with the authors.
Open Access This article is distributed under the terms of the Creative Commons Attribution 4.0 International License (http:// creativecommons.org/licenses/by/4.0/), which permits unrestricted use, distribution, and reproduction in any medium, provided you give appropriate credit to the original author(s) and the source, provide a link to the Creative Commons license, and indicate if changes were made.

\section{References}

Adar Z, Griffin J (1976) Uncertainty and the choice of pollution control instruments. J Environ Econ Manag 3:178-188

Akerlof GA (1970) The market for 'lemons': quality uncertainty and the market mechanism. Q J Econ 84(3):488-500

Albertson K, Aylen J (1996) Modelling the Great Lakes freeze: forecasting and seasonality in the market for ferrous scrap. Int J Forecast 12 : 345-359

Anderson RC, Spiegelman RD (1977) Tax policy and secondary material use. J Environ Econ Manag 4:68-82

Andersson C, Stage J (2018) Direct and indirect effects of waste management policies on household waste behaviour: the case of Sweden. Waste Manag 76:19-27

Angus A, Rivas Casado M, Fitzsimons D (2012) Exploring the usefulness of a simple linear regression model for understanding price movements of selected recycled materials in the UK. Resour Conserv Recycl 60:10-19

Aylen J, Albertson K (2006) Markets in ferrous scrap for steelmaking. Ironmak Steelmak 33(3):203-212

Baltagi BH (2005) Econometric analysis of panel data. John Wiley \& Sons Ltd., West Sussex

Barnett DF, Crandall RW (1986) Up from the ashes: the rise of the steel minimill in the United States. The Brookings Institution, Washington, D.C.

Bennear LS, Stavins RN (2007) Second-best theory and the use of multiple policy instruments. Environmental \& Resource Economics 37: 111-129

Blomberg J, Hellmer S (2000) Short-run demand and supply elasticities in the west European market for secondary aluminium. Resources Policy 26:39-50

Blomberg J, Söderholm P (2009) The economics of secondary aluminium supply: an econometric analysis based on European data. Resour Conserv Recycl 53:455-463

Bonzcar ES, Tilton JE (1975) An economic analysis of the determinants of metal recycling in the US: a case study of secondary copper. US Bureau of Mines, Washington, DC

Bureau of International Recycling (BIR) (2018) World steel recycling in figures 2013-2017. Ferrous Division, Brussels

Calcott, P., and M. Walls (2000). Can downstream waste disposal policies encourage upstream 'Design for Environment'? American Economic Review: AEA Papers and Proceedings 90(2), 233-237

Calcott P, Walls M (2005) Waste, recycling, and 'design for environment': roles for markets and policy instruments. Resour Energy Econ 27:287-305

Carlén B, Mandell S, Carling A (2005) Svensk klimatpolitik under nationellt respektive avräkningsmål, Report ER 2005:29. Swedish Energy Agency, Eskilstuna

Carlsen, E. H. (1980) Aluminium recycling coefficients. Business Economics, January, 41-46

Associates CR (1971) An economic analysis of the aluminium industry. General Services Administration, Washington D.C

da Cruz NF, Ferreira S, Cabral M, Simões P, Marques RC (2014) Packaging waste recycling in Europe: is the industry paying for it? Waste Manag 34(2):298-308

Dinan TM (1993) Economic efficiency effects of alternative policies for reducing waste disposal. J Environ Econ Manag 25:242-256 
Ecotec (2000). Policy instruments to correct market failure in the demand for secondary materials. Report prepared by Ecotec Research and Consulting Ltd., Birmingham, UK

Edgren JA, Moreland KW (1989) An econometric analysis of paper and wastepaper markets. Resour Energy 11:299-319

Edwards R (1979) Price expectations and the supply of wastepaper. J Environ Econ Manag 6:332-340

Eichner T (2005) Imperfect competition in the recycling industry. Metroeconomica 56(1):1-24

Ejdemo T, Söderholm P (2008) Steel scrap markets in Europe and the USA. Minerals \& Energy 23(2):57-73

Ekvall T (2000) A market-based approach to allocation at open-loop recycling. Resour Conserv Recycl 29:91-109

Ekvall T, Sundqvist J-O, Hemström K, Jensen C (2014) Stakeholder analysis of incineration tax, raw material tax, and weight-based waste fee. Report C74. IVL Swedish Environmental Research Institute, Stockholm

European Commission (2005). Thematic strategy on the sustainable use of natural resources. COM (2005) 670, Brussels

European Commission (2015). Closing the loop - an EU action plan for the circular economy. $\operatorname{COM}(2015) 614 / 2$, Brussels

European Environment Agency (EEA) (2008). Effectiveness of environmental taxes and charges for managing sand, gravel and rock extraction in selected EU countries. EEA Report No. 2/2008, Copenhagen, Denmark

European Environment Agency (EEA) (2017). Circular by design. Products in the circular economy. EEA Report No. 6/2017, Copenhagen, Denmark

Finnveden G, Bisaillon M, Noring M, Stenmarck Å, Sundberg J, Sundqvist J-O, Tyskeng S (2012) Developing and evaluating new policy instruments for sustainable waste management. International Journal of Environment and Sustainable Development 11(1):19-31

Finnveden G, Ekvall T, Arushanyan Y, Bisaillon M, Henriksson G, Gunnarsson Östling U, Ljunggren Söderman M, Sahlin J, Stenmarck Å, Sundberg J, Sundqvist J-O, Svenfelt A, Söderholm P, Björklund A, Eriksson O, Forsfält T, Guath M (2013) Policy instruments towards a sustainable waste management. Sustainability 5:841-881

Fisher FM, Cootner PH, Baily MN (1972) An econometric model of the world copper industry. Bell J Econ Manag Sci 3(2):568-609

Fullerton D, Kinnaman TC (1995) Garbage, recycling and illicit burning or dumping. J Environ Econ Manag 29:78-91

Fullerton D, Wu W (1998) Policies for green design. J Environ Econ Manag 25:242-256

Gaballah I, Kanari N (2001) Recycling policy in the European Union. J Miner Met Mater Soc 53(11):24-27

Gómez F, Guzmán JI, Tilton JE (2007) Copper recycling and scrap availability. Resour Policy 32:183-190

Goulder LH, Parry IWH (2008) Instrument choice in environmental policy. Rev Environ Econ Policy 2(2):152-174

Hage O (2007) The Swedish producer responsibility for paper packaging: an effective waste management policy? Resour Conserv Recycl 51: 314-344

Hashimoto S, Fischer-Kowalski M, Sangwon M, Xuemei B (2012) Greening growing giants: a major challenge of our planet. J Ind Ecol 16:459-466

Heshmati A (2017) A review of the circular economy and its implementation. International Journal of Green Economics 11(3/4):251-288

International Council on Metals and the Environment (ICME) (1996) Non-ferrous metals recycling: a complement to primary metals production. ICME, Ottawa

Ino H (2011) Optimal environmental policy for waste disposal and recycling when firms are not compliant. J Environ Econ Manag 62:290-308
Jaffe AB, Newell RG, Stavins RN (2003) Technological change and the environment. In: Mäler K-G, Vincent JR (eds) Handbook of environmental economics, vol 1. Elsevier Science, Amsterdam

Kinkley CC, Lahiri K (1984) Testing the rational expectations hypothesis in a secondary materials market. J Environ Econ Manag 11:282-291

Legg, D. (2007). Effectiveness of environmental taxes and charges for managing sand, gravel, and rock extraction in selected EU countries: Sweden, ETC/RWM working paper 2007/5, European Topic Centre on Resource and Waste Management

Lundmark R, Söderholm P (2003) Structural changes in Swedish wastepaper demand: a variable cost function approach. J For Econ 9:4163

Lundmark R, Söderholm P (2004) Estimating and decomposing the rate of technical change in the Swedish pulp and paper industry: a general index approach. Int J Prod Econ 91(1):17-35

Mansikkasalo A, Lundmark R, Söderholm P (2014) Market behavior and policy in the recycled paper industry: a critical review of price elasticity research. Forest Policy Econ 38:17-29

Milios L (2018) Advancing to a circular economy: three essential ingredients for a comprehensive policy mix. Sustain Sci 13(3):861-878

Matsueda N, Nagase Y (2012) An economic analysis of the packaging waste recovery note system in the UK. Resour Energy Econ 34:669679

Ministry of Finance (2003). Naturgrusskatten: Måluppfyllelse och konsekvenser (the tax on natural gravel: goal fulfilment and consequences). Stockholm, Sweden

Nestor DV (1992) Partial static equilibrium model of newsprint recycling. Appl Econ 24:411-417

Nicolli F, Johnstone N, Söderholm P (2012) Resolving failures in recycling markets: the role of technological innovation. Environ Econ Policy Stud 14(3):261-288

Nordic Council of Ministers (2002). The use of economic instruments in Nordic environmental policy 1999-2001, TemaNord 2002:581, Copenhagen

O’Doherty R, Bailey I, Collins A (2003) Regulatory failure via market evolution: the case of UK packaging recycling. Environment and Planning C: Government and Policy 21:579-559

Oosterhuis FH, Bartelings H, Linderhof VGM, van Beukering PJH (2009) Economic instruments and waste policies in the Netherlands. In: Report R-09/01, Institute for Environmental Studies (IVM). Vrije University, Amsterdam

Palmer K, Sigman HA, Walls M (1997) The cost of reducing municipal solid waste. J Environ Econ Manag 33:128-150

Palmer K, Walls M (1999) Extended product responsibility: an economic assessment of alternative policies, discussion paper 99-12. Resources for the Future, Washington, DC

Radetzki M, Wårell L (2017) A handbook of primary commodities in the global economy, Second edn. Cambridge University Press, New York

Reid, M. (2003). A strategy for construction and demolition waste as recycled aggregates. WRAP Research and Development Report: Aggregates, September, United Kingdom

Samakovlis E (2003) The relationship between waste paper and other inputs in the Swedish paper industry. Environ Resour Econ 25: 191-212

Sigman HA (1995) A comparison of public policies for lead recycling. RAND J Econ 26(3):452-478

Slade ME (1980a) An econometric model of the U.S. secondary copper industry: recycling versus disposal. J Environ Econ Manag 7:123141

Slade ME (1980b) The effects of higher energy prices and declining ore quality - copper-aluminium substitution and recycling in the USA. Resour Policy 6:223-239

Söderholm P (2008) The political economy of international green certificate markets. Energy Policy 36(6):2051-2062 
Söderholm P (2011) Taxing virgin natural resources: lessons from aggregates taxation in Europe. Resour Conserv Recycl 55(11):911-922

Söderholm P, Christiernsson A (2008) Policy effectiveness and acceptance in the taxation of environmentally damaging chemical compounds. Environ Sci Pol 11(3):240-252

Söderholm P, Tilton JE (2012) Material efficiency: an economic perspective. Resour Conserv Recycl 61:75-82

Stavins RN (1995) Correlated uncertainty and policy instrument choice. J Environ Econ Manag 30:218-232

Stollery KR (1983) Secondary supply of copper and ferrous metals and Canadian metal markets, Centre for Resource Studies, technical paper no. 3. Queens University, Kingston

Suan Tan C (1987) An econometric analysis of the world copper market, World Bank Staff Commodity Working Papers No. 20. World Bank, Washington D.C.

Symonds, Argus, COWI, and PRC Bouwcentrum (1999) Construction and demolition waste: management practices and their economic impacts, report prepared for the European Commission, DG XI, Brussels

Tilton, JE (1992) Economics of the mineral industries. In Hartman HL (ed) SME engineering handbook, 2nd edn. SME, Littleton, p 47-62

Tilton JE (2000) The future of recycling. Resources Policy 25:197-204

Tilton JE, Guzmán JI (2016) Mineral economics and policy. u, Washington, DC
Van Den Bergh JCJM, Janssen MA (eds) (2005) Economics of industrial ecology: materials, structural change, and spatial scales. MIT Press, Cambridge

Velis C (2014) Global recycling markets, Plastic Waste. Report prepared by FUELogy on behalf of international solid waste association (ISWA) - globalization and waste management task force. ISWA, Vienna

Wagenhals G (1984) The world copper market—structure and econometric model. Springer Verlag, Berlin

Walls M (2003) Role of economics in extended producer responsibility: making policy choices and setting policy goals. Discussion paper 03-11. Resources for the Future, Washington, DC

Walls M, Palmer K (2001) Upstream pollution, downstream waste disposal, and the design of comprehensive environmental policies. $\mathrm{J}$ Environ Econ Manag 41:94-108

Weitzman M (1974) Prices vs. quantities. Rev Econ Stud 41:447-491

Publisher's note Springer Nature remains neutral with regard to jurisdictional claims in published maps and institutional affiliations. 